\title{
Studies on Frequency Response Characteristics of High-Speed Railway Train End Relationship Test System with Flexible Bases
}

\author{
Zhiqiang Zhang, Dacheng Cong, Zhidong Yang *, Yunfei Cai and Junwei Han
}

Citation: Zhang, Z.; Cong, D.; Yang, Z.; Cai, Y.; Han, J. Studies on Frequency Response Characteristics of High-Speed Railway Train End Relationship Test System with Flexible Bases. Energies 2021, 14, 6147. https://doi.org/10.3390/en14196147

Academic Editors: Krzysztof Szabat and Luigi Fortuna

Received: 2 August 2021

Accepted: 21 September 2021

Published: 27 September 2021

Publisher's Note: MDPI stays neutral with regard to jurisdictional claims in published maps and institutional affiliations.

Copyright: (c) 2021 by the authors. Licensee MDPI, Basel, Switzerland. This article is an open access article distributed under the terms and conditions of the Creative Commons Attribution (CC BY) license (https:// creativecommons.org/licenses/by/ $4.0 /)$.

\author{
State Key Laboratory of Robotics and System, School of Mechatronics Engineering, Harbin Institute of \\ Technology, West Dazhi Street No. 92, Harbin 150000, China; zhangzhiqiang_hit@163.com (Z.Z.); \\ congdacheng_hit@163.com (D.C.); 17B908052@stu.hit.edu.cn (Y.C.); hjw@hope.hit.edu.cn (J.H.) \\ * Correspondence: yangzhidong@hit.edu.cn
}

\begin{abstract}
A train end relationship test system was installed with a Stewart parallel robot on the reaction bases perpendicular to the ground, to test the fatigue and durability of train end relationship components, such as the transfixion way of a high-speed railway train. The flexibility of the reaction bases affected the test accuracy of the train end relationship components within a test frequency band range. In this paper, a coupling characteristic model was established between the flexible bases and the parallel robot. Then, the analytical relationship was analyzed between the natural frequency of the bases and the natural frequency of the parallel robot. Moreover, a design criterion was proposed for the natural frequency of the reaction bases. It was considered that when the natural frequency of the bases was not less than five times the natural frequency of the parallel robot, the influence of the flexibility of the bases on the test accuracy can be ignored. The validity of the design criterion was verified by the simulation results.
\end{abstract}

Keywords: stewart parallel robot; flexible reaction base; dynamic coupling; natural frequency

\section{Introduction}

With the rapid development of railway transportation, speed and load carrying capacity has improved significantly during the past few decades. Many series of high-speed trains have been developed with speeds of $200-400 \mathrm{~km} / \mathrm{h} \mathrm{[1,2].} \mathrm{The} \mathrm{improvement} \mathrm{of} \mathrm{train}$ speeds produces a highly complicated dynamic characteristic to the railway system [3,4].

Considering the stringent requirements of the safety and reliability of high-speed railway trains, researchers have developed many test techniques, including theory principles, test-methods and corresponding test-rigs. Zhang [5] analyzed the dynamic interaction between train and track, the pantograph-catenary system, the power supply system, and the airflow of high-speed railway systems. Makino [6] reviewed the fatigue damage tolerance of high-speed railway axles in Japan and discussed the fatigue design method. Guo [7] studied the fatigue life assessment of bogie frames, which is the most important mechanical component of high-speed trains. Lu [8] analyzed the thermomechanical fatigue damage and rotating loading method, which is more suitable to simulate the true multiaxial behavior and out-of-phase failure status. Bustos [9] proposed an Empirical Mode Decomposition-based identification method for high-speed trains, which is a practical earlydetection method and may reduce maintenance costs. The train end includes aisle, inner windshield, outer rubber windshield, mechanical connection components (train coupler), and electric and electronic connection cable components. The train end is an important part of high-speed trains, which suffers from a complex multidirectional time-varying load, due to the relative motion between adjacent cars in the train.

A comprehensive test system for the train end relationship was used for the comprehensive performance test of high-speed railway train end components; its structure 
is shown in Figure 1. With a self-designed Stewart parallel robot, the test accurately reproduced the boundary conditions of train end displacement, and velocity and force, and simulated the motion characteristics of a high-speed railway train under complex line conditions, i.e., curves and turnouts, and researched the strength, stiffness, fatigue durability and reliability of the train end components, such as the transfixion way and jumper cable.

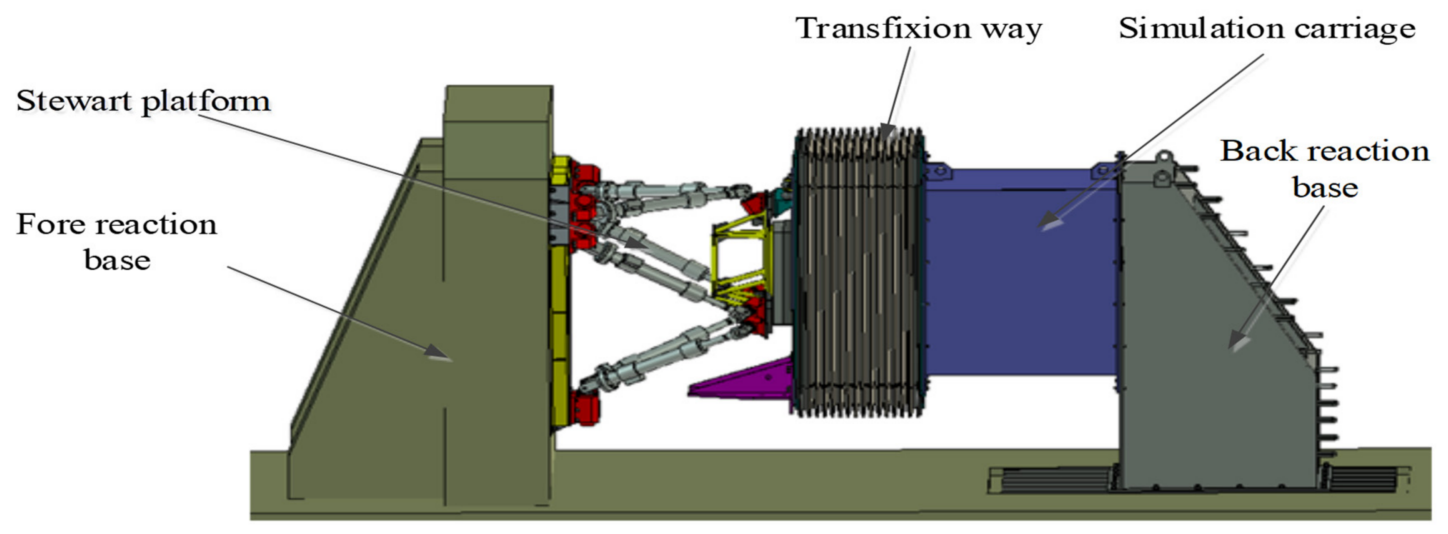

Figure 1. Comprehensive test system for train end relationship.

The Stewart parallel robot was usually installed on rigid bases parallel to the ground to accurately reproduce the actual motion conditions of ships, aircraft, and weapon systems $[10,11]$, and it has been very successful in its structural analysis and optimization, and in its control strategy research, etc. In the comprehensive test of the train end relationship, the parallel robot was installed on the reaction bases perpendicular to the ground. As the heights of the loading test points of the train end relationship components were generally not less than $2.5 \mathrm{~m}$, the stiffness of the reaction bases for the parallel robot was reduced, and the reaction bases became flexible bases. The flexible bases led to a decrease in the kinematic and dynamic performance of the parallel motion robot, resulting in an increase in motion error, a reduction in bandwidth, and mechanism resonance. Aiming at addressing the flexibility of the parallel robot, Amir Rezaei studied the stiffness of a 3-PSP parallel mechanism with a flexible moving platform, and proposed two stiffness-models and stiffness-analysis methods thereof based on the principle of the virtual work and the Karnife's theorem [12]. Mahdi Sharifnia and Alireza Akbarzadeh provided analytical solutions to the dynamics and vibration characteristics of a 3-PSP parallel mechanism with a flexible moving platform [13]. Gengxiang Wang analyzed the influence of a flexible platform and a spherical joint clearance of a 4-SPSCU parallel mechanism on the dynamic performance, and he believed that the flexibility of the platform had little influence on the dynamic performance, and that the platform absorbed the energy generated by the impact of the spherical joint clearance [14]. Wei Wei simplified flexible bases into single-degree-offreedom masses, springs, and damping models, and studied the influence of the flexible bases on the performance of a parallel mechanism system and the control strategy [15]. In summary, concerns have largely been focused on the influence of the flexibility of the platform and the flexibility of the driving mechanism on system characteristics [16-21].

In this paper, a mathematical model of a comprehensive test system was established for the train end relationship, with six-degree-of-freedom flexible bases. The coupling characteristics between the six-degree-of-freedom flexible bases and the parallel robot, and their influence on the performance of the comprehensive test system for the train end relationship, were studied, and a design criterion for the natural frequency of the flexible reaction bases was proposed that satisfied the train end relationship test accuracy. 


\section{Modeling of Test System for Train End Relationship}

\subsection{Modeling of Stewart Parallel Robot with Flexible Reaction Bases}

\subsubsection{Kinematical Modeling}

A physical model of the comprehensive test system for the train end relationship can be described in Figure 2. $K_{b}$ and $C_{b}$ represented the six-dimensional stiffness and damping of the fore reaction base, respectively; $c^{m}$ represented a matrix composed of lower hinge point coordinates of the Stewart platform; $d^{p}$ represented a matrix composed of upper hinge point coordinates of the Stewart platform; $K_{g}$ and $C_{g}$ represented the sixdimensional stiffness and damping of the transfixion way of the train, respectively, and $\boldsymbol{K}_{t}$ and $C_{t}$ represented the six-dimensional stiffness and damping of the back reaction base, respectively.

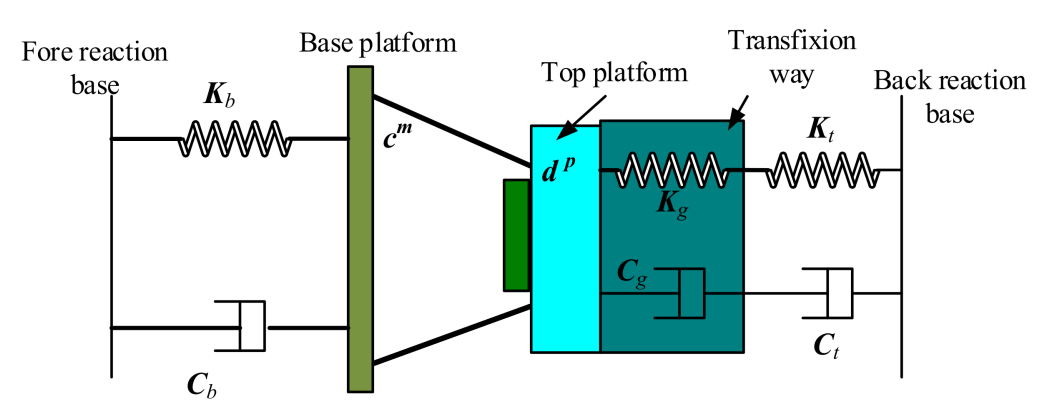

Figure 2. Model of comprehensive test system for train end relationship.

Since the stiffness of the train end relationship component was much smaller than that of the reaction base, the spring-damping system on the right side of the upper platform can be considered as a free end. The model of the test system for the train end relationship can be simplified, as shown in Figure 3.

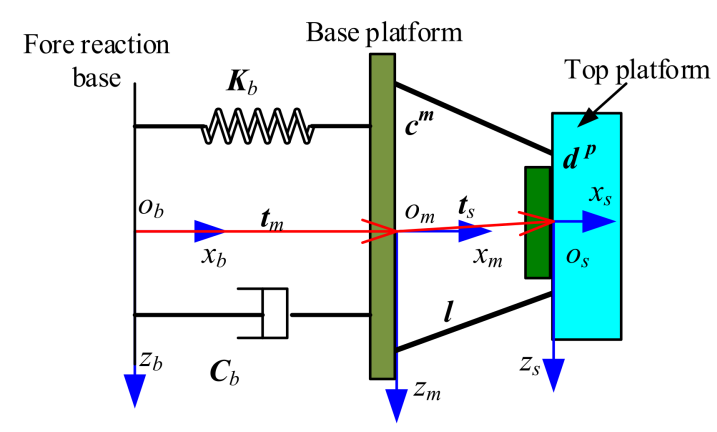

Figure 3. Simplified model of comprehensive test system for train end relationship.

In order to describe the motion of the test platform in the physical space, three coordinate systems, as shown in Figure 3, were established. A platform-conjoined coordinate system $\{s\} o_{s}-x_{s} y_{s} z_{s}$ was established at the center position of the upper hinge to describe the position and posture change of the upper platform relative to the base platform. A conjoined coordinate system $\{m\} o_{m}-x_{m} y_{m} z_{m}$ was established at the center of the lower hinge point to describe the deformation caused by the flexibility of the base. An inertial coordinate system $\{b\} o_{b}-x_{b} y_{b} z_{b}$ was also located at the center of the lower hinge point and in the same direction as the conjoined coordinate system $\{m\}$.

In order to describe the flexible deformation of the base, generalized coordinates $\boldsymbol{q}_{m}=\left(\psi_{m}, \theta_{m}, \varphi_{m}, x_{m}, y_{m}, z_{m}\right)^{T}$ were defined, where the first three elements of the generalized coordinates represented angular deformation of the base, and their Euler transformation sequence was 3-2-1. The vector $t_{m}$ composed of the last three elements represented displacement caused by the deformation of the base, and the corresponding Euler transformation matrix was $\boldsymbol{R}_{b m}$. In the same way, generalized coordinates $\boldsymbol{q}_{s}=\left(\psi_{s}, \theta_{s}, \varphi_{s}, x_{s}, y_{s}\right.$, 
$\left.z_{s}\right)^{T}$ were used to describe the motion of the upper platform relative to the base, where the first three elements of the generalized coordinates represented the posture of the upper platform relative to the base, and their Euler transformation sequence was also 3-2-1. The vector $\boldsymbol{t}_{s}$ composed of the last three elements represented the position of the upper platform relative to the base, and the corresponding Euler transformation matrix was $\boldsymbol{R}_{m s}$. After the coordinate systems were established and the generalized coordinates were defined, the motion of each component of the parallel robot can be uniquely determined according to the relationship between the motion coordinate system and the inertial coordinate system. The above three consecutive transformations can be represented by the following rotation transformation matrix, i.e.,

$$
\boldsymbol{R}_{b m}=\left[\begin{array}{ccc}
\mathrm{c} \psi_{m} \mathrm{c} \theta_{m} & \mathrm{c} \psi_{m} \mathrm{~s} \theta_{m} \mathrm{~s} \varphi_{m}-\mathrm{s} \psi_{m} \mathrm{c} \varphi_{m} & \mathrm{c} \psi_{m} \mathrm{~s} \theta_{m} \mathrm{c} \varphi_{m}-\mathrm{s} \psi_{m} \mathrm{~s} \varphi_{m} \\
\mathrm{~s} \psi_{m} \mathrm{c} \theta_{m} & \mathrm{~s} \psi_{m} \mathrm{~s} \theta_{m} \mathrm{~s} \varphi_{m}+\mathrm{c} \psi_{m} \mathrm{c} \varphi_{m} & \mathrm{~s} \psi_{m} \mathrm{~s} \theta_{m} \mathrm{c} \varphi_{m}-\mathrm{c} \psi_{b} \mathrm{~s} \varphi_{m} \\
-\mathrm{s} \theta_{m} & \mathrm{c} \theta_{m} \mathrm{~s} \varphi_{m} & \mathrm{c} \theta_{m} \mathrm{c} \varphi_{m}
\end{array}\right],
$$

where $\mathrm{s}(\cdot)=\sin (\cdot), \mathrm{c}(\cdot)=\cos (\cdot)$.

Thus, the three Euler angles determined the posture of the upper platform relative to the base. In the same way, the Euler angles corresponding to the posture of the upper platform relative to the base can also be brought into the above equation to obtain $\boldsymbol{R}_{m s}$. The following generalized velocity was defined:

$$
\begin{aligned}
& \dot{\boldsymbol{q}}_{m}=\left[\dot{\boldsymbol{t}}_{m}, \boldsymbol{\omega}_{m}\right]^{T} \\
& \dot{\boldsymbol{q}}_{\boldsymbol{s}}=\left[\dot{\boldsymbol{t}}_{s}, \boldsymbol{\omega}_{s m}\right]^{T}
\end{aligned}
$$

where $\boldsymbol{\omega}_{m}$ was an angular velocity vector of base deformation; $\dot{\boldsymbol{q}}_{m}$ was a generalized velocity of base deformation; $\omega_{s m}$ was an angular velocity vector of the upper platform relative to the base; $\dot{\boldsymbol{q}}_{S}$ was a generalized velocity of the upper platform relative to the base.

According to the space-vector relationship, the length vectors $l_{i}(i=1, \cdots, 6)$ of 6 hydraulic cylinders can be expressed as:

$$
\boldsymbol{l}_{i}=\boldsymbol{t}_{s}+\boldsymbol{R}_{m s} \boldsymbol{d}_{i}^{s}-c_{i}^{m},
$$

where $\boldsymbol{R}_{m s}$ was a rotation transformation matrix; $\boldsymbol{d}_{i}^{s}$ was a radial vector of the upper hinge point in the platform coordinate system; $c_{i}^{m}$ was a radial vector of the lower hinge point in the carrier coordinate system.

The angular velocity of the platform should satisfy the following relationship:

$$
\boldsymbol{\omega}_{s}=\boldsymbol{R}_{b_{m}}^{T} \boldsymbol{\omega}_{m}+\boldsymbol{\omega}_{s m}=\left[0_{3 \times 3}, \boldsymbol{I}_{3 \times 3}, 0_{3 \times 3}, \boldsymbol{R}_{b_{m}}^{T}\right]\left[\begin{array}{c}
\dot{\boldsymbol{q}}_{s} \\
\dot{\boldsymbol{q}}_{m}
\end{array}\right]=\boldsymbol{J}_{\omega} \dot{\boldsymbol{q}}=\left[\boldsymbol{J}_{\omega s}, \boldsymbol{J}_{\omega b}\right]\left[\begin{array}{c}
\dot{\boldsymbol{q}}_{s} \\
\dot{\boldsymbol{q}}_{m}
\end{array}\right]
$$

$v_{\mathcal{C}}$ was supposed as the movement velocity of the lower hinge point, then

$$
\boldsymbol{v}_{c i}=\boldsymbol{R}_{b m}^{T} \dot{\boldsymbol{t}}_{m}+\boldsymbol{\omega}_{m} \times \boldsymbol{c}_{i}^{m}
$$

where $\boldsymbol{\omega}_{m}$ was an angular velocity vector of $\{m\}$ relative to $\{b\}$, and $\dot{\boldsymbol{t}}_{m}$ was a velocity vector of $\{m\}$ center $o_{m}$ in $\{b\}$.

On the other hand, $v_{d}$ was the movement velocity of the upper hinge point, then

$$
\boldsymbol{v}_{d i}=\boldsymbol{R}_{b m}^{T} \dot{\boldsymbol{t}}_{m}+\dot{\boldsymbol{t}}_{s}+\boldsymbol{\omega}_{\mathrm{s}} \times \boldsymbol{R}_{m s} \boldsymbol{d}_{i}^{\mathrm{s}}
$$

Equation (7) was expressed as the following transformed forms:

$$
\boldsymbol{v}_{c i}=\left[\boldsymbol{R}_{b m}^{T},-\mathrm{S}\left(c_{i}^{m}\right)\right] \dot{\boldsymbol{q}}_{m}=\boldsymbol{J}_{c i, q m} \dot{\boldsymbol{q}}_{m}
$$




$$
\boldsymbol{v}_{d i}=\left[\boldsymbol{I}_{3 \times 3},-\boldsymbol{S}\left(\boldsymbol{R}_{m s} \boldsymbol{d}_{i}^{S}\right), \boldsymbol{R}_{b m}^{T},-\boldsymbol{S}\left(\boldsymbol{t}_{s}+\boldsymbol{R}_{m s} \boldsymbol{d}_{i}^{S}\right) \boldsymbol{R}_{b m}^{T}\right] \dot{\boldsymbol{q}}=\boldsymbol{J}_{d i, q} \dot{\boldsymbol{q}}
$$

In addition, if $\rho_{p}$ was supposed as the position vector of the integrated center of mass of the platform under the platform system, then the center-of-mass velocity of the platform can be obtained from Equation (9):

$$
\boldsymbol{v}_{p}=\left[\boldsymbol{I}_{3 \times 3},-\boldsymbol{S}\left(\boldsymbol{R}_{m s} \boldsymbol{\rho}_{p}\right), \boldsymbol{R}_{b m}^{T},-\boldsymbol{S}\left(\boldsymbol{t}_{s}+\boldsymbol{R}_{m s} \boldsymbol{\rho}_{p}\right) \boldsymbol{R}_{b m}^{T}\right] \dot{\boldsymbol{q}}=\boldsymbol{J}_{p} \dot{\boldsymbol{q}}=\left[\boldsymbol{J}_{p s}, \boldsymbol{J}_{p b}\right]\left[\begin{array}{c}
\dot{\boldsymbol{q}}_{s} \\
\dot{\boldsymbol{q}}_{m}
\end{array}\right]
$$

where $\boldsymbol{I}_{3 \times 3}$ was a $3 \times 3$ unit matrix; $\boldsymbol{\omega}_{s}$ was an angular velocity vector of the upper platform; $S(\cdot)$ was a skew symmetric matrix of vector; $J_{c i, q m}$ was a Jacobian matrix between the velocities of the lower hinge points of the platform; $J_{d i, q}$ was a Jacobian matrix between the velocities of upper hinge points of the platform; $\dot{\boldsymbol{q}}=\left[\dot{\boldsymbol{q}}_{S}^{T}, \dot{\boldsymbol{q}}_{m}^{T}\right]^{T}$.

The extension velocity of the hydraulic cylinder can be given by the following equation:

$$
\dot{l}_{i}=\boldsymbol{l}_{n i}^{T}\left(\boldsymbol{v}_{d i}-\boldsymbol{v}_{c i}\right)
$$

where $\boldsymbol{l}_{n i}$ was a unit direction vector of the hydraulic cylinder:

$$
l_{n i}=\frac{l_{i}}{\left|l_{i}\right|}
$$

Considering that the test system was actuated by six hydraulic actuators, Equation (11) can be written as a matrix equation:

$$
\dot{\boldsymbol{l}}=\left[\begin{array}{ll}
\boldsymbol{L}_{n}^{T} & \left(\boldsymbol{R}_{m s} \boldsymbol{d}^{\boldsymbol{s}} \times \boldsymbol{L}_{n}\right)^{T}
\end{array}\right]\left[\begin{array}{c}
\dot{\boldsymbol{t}}_{s} \\
\boldsymbol{\omega}_{s m}
\end{array}\right]=\boldsymbol{J}_{l q s} \dot{\boldsymbol{q}}_{s}
$$

where $\dot{l}$ was a vector matrix composed of extension velocities of hydraulic cylinders; $\boldsymbol{L}_{n}$ was a matrix composed of unit-direction vectors of hydraulic cylinders; $d^{S}$ was a coordinate matrix of the upper hinge point in the platform coordinate system; $\boldsymbol{J}_{l q s}$ was a Jacobian matrix from generalized velocities of the system to extension velocities of the hydraulic cylinders.

\subsubsection{Kinetic Analysis}

The equivalent mass and inertia of the platform body and load were large; therefore, the influence of the mass of the piston rod and cylinder barrel, and the friction of the hydraulic cylinder and the connecting hinge, can be ignored. In this way, the Stewart platform under the flexible base can be regarded as a single rigid-body system. For such a single rigid-body, the dynamic equation can be directly obtained from the Kane equation.

The inertial force and moment of the platform were projected to the degree-of-freedom space of the platform to obtain the generalized inertial force as:

$$
\boldsymbol{F}_{p}^{I}=-\boldsymbol{J}_{p}^{T} m_{p} \dot{\boldsymbol{v}}_{p}-\boldsymbol{J}_{\omega s}^{T}\left(\boldsymbol{I} \dot{\boldsymbol{\omega}}_{s}+\boldsymbol{S}\left(\boldsymbol{\omega}_{s}\right) \boldsymbol{I} \boldsymbol{\omega}_{s}\right)
$$

where $I$ was an inertia matrix of the lower platform of the conjoined system.

In the same way, the generalized main power of the platform can be solved as:

$$
\boldsymbol{F}_{p}^{a}=\boldsymbol{J}_{p}^{T} m_{p} \boldsymbol{g}+\boldsymbol{J}_{l q s}^{T} f_{a}
$$

where $\boldsymbol{I}=\boldsymbol{R}_{m s} \boldsymbol{I}_{p s} \boldsymbol{R}_{m s}^{T}, m_{p}$ and $\boldsymbol{I}_{p s}$ were the inertia matrices of mass of the upper platform in the platform coordinate system. According to the $\mathrm{D}^{\prime}$ Alembert principle, Equations (14) and (15) were combined to obtain a dynamic equation of joint space:

$$
\boldsymbol{M}_{l} \ddot{\boldsymbol{l}}+\boldsymbol{C}_{l} \dot{\boldsymbol{l}}-\boldsymbol{G}_{l}+\boldsymbol{M}_{m} \ddot{\boldsymbol{q}}_{m}+\boldsymbol{C}_{m} \dot{\boldsymbol{q}}_{m}=f_{a}
$$


$M_{l}$ was a mass matrix; $C_{l}$ was a centrifugal force and Coriolis force matrix; $G_{l}$ was a gravity vector equation. The last two items on the left of Equation (16) indicated the influence of the flexible deformation of the base on the Stewart platform.

\subsection{Flexible Base Model}

The deformation of each degree of freedom of the flexible base was:

$$
\boldsymbol{M} \ddot{\boldsymbol{q}}_{m}+\boldsymbol{C} \dot{\boldsymbol{q}}_{m}+\boldsymbol{K} \boldsymbol{q}_{m}=-\boldsymbol{J}_{l m}^{T} f_{a}
$$

where $\boldsymbol{M}=\operatorname{diag}\left\{I_{b 1}, I_{b 2}, I_{b 3}, m_{b}, m_{b}, m_{b}\right\}, \boldsymbol{C}=\operatorname{diag}\{0.05,0.05,0.05,0.05,0.05,0.05\}$, and $K=\operatorname{diag}\left\{k_{b}, k_{b}, k_{b}, k_{b}, k_{b}, k_{b}\right\}$ represented a mass matrix and a stiffness matrix of each degree of freedom, respectively; $\boldsymbol{J}_{l m}$ was a projection matrix, which was used to project the actuating force of the hydraulic cylinder onto each degree of freedom of the base.

\subsection{Hydraulic Drive System Model}

The parallel robot was actuated by six identical hydraulic servo power-mechanisms, and the principle diagram of each hydraulic servo power-mechanism was shown in Figure 4 [13].

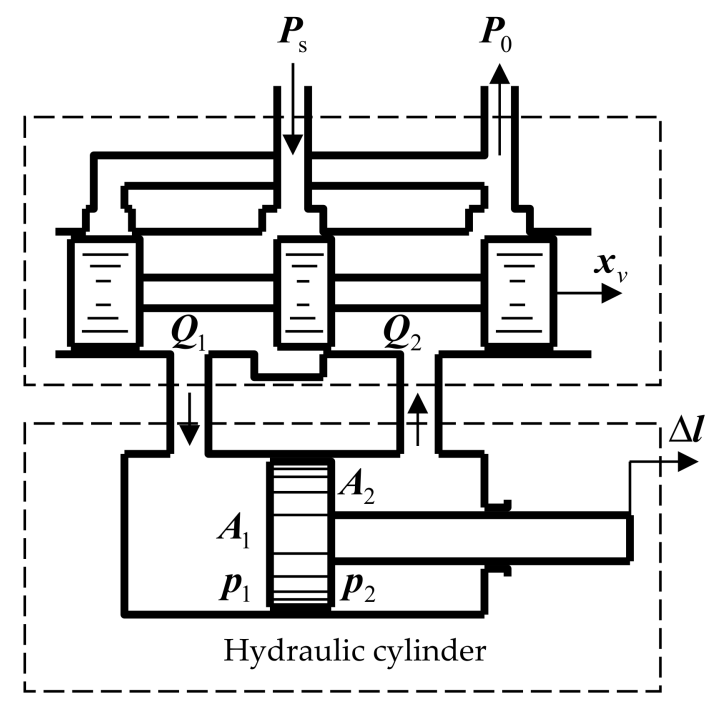

Figure 4. Diagram of hydraulic servo control system.

Six hydraulic system-dynamics models can be expressed by differential equations in vector form, which can be written as the following equations.

Flow equation of servo valve:

$$
Q_{L}=K_{q} x_{v}-K_{c} P_{L}
$$

Continuity equation of hydraulic cylinder:

$$
\boldsymbol{Q}_{L}=A \dot{\boldsymbol{l}}+C_{t c} \boldsymbol{P}_{L}+C_{r} \dot{\boldsymbol{P}}_{L}
$$

Force balance equation between the hydraulic drive system and the load:

$$
\boldsymbol{P}_{L} A=f_{a}
$$

where $K_{q}$ was a flow gain of the servo valve; $K_{c}$ was a flow pressure coefficient of the servo valve; $C_{t}$ was a total leakage coefficient of the hydraulic cylinder; $A$ was the effective area of the hydraulic cylinder; $f_{a}$ was the driving force of each cylinder of the hydraulic servo system; $\boldsymbol{P}_{L}$ was the pressure of the load, and $C_{r}$ was a compression coefficient of hydraulic cylinder oil. 
Based on the Stewart parallel robot model, the flexible base model, and the hydraulic drive system model, a complete dynamic model of the comprehensive test system for the train end relationship was obtained as:

$$
\begin{gathered}
\boldsymbol{M}_{l} \ddot{\boldsymbol{l}}+\boldsymbol{C}_{l} \dot{\boldsymbol{l}}-\boldsymbol{G}_{l}+\boldsymbol{M}_{m} \ddot{\boldsymbol{q}}_{m}+\boldsymbol{C}_{m} \dot{\boldsymbol{q}}_{m}=\boldsymbol{P}_{L} A \\
\boldsymbol{M} \ddot{\boldsymbol{q}}_{m}+\boldsymbol{C} \dot{\boldsymbol{q}}_{m}+\boldsymbol{K} \boldsymbol{q}_{m}=-\boldsymbol{J}_{l m}^{T} \boldsymbol{P}_{L} A \\
\dot{\boldsymbol{P}}_{L}=\frac{1}{C_{r}}\left(K_{q} \boldsymbol{x}_{v}-A \dot{\boldsymbol{l}}-K_{c e} \boldsymbol{P}_{L}\right)
\end{gathered}
$$

Due to the flexibility of the base, the actual posture of the platform was calculated by combining the posture of the platform relative to the base and the deformation of the base:

$$
\begin{gathered}
\boldsymbol{R}=\boldsymbol{R}_{b m} \boldsymbol{R}_{m s} \\
\boldsymbol{t}=\boldsymbol{t}_{m}+\boldsymbol{R}_{b m} \boldsymbol{t}_{s}
\end{gathered}
$$

Because the output model of the control system cannot be expressed by the dynamic equation of (21), Equation (21) can be rewritten as Equation (26) by transforming Equations (21), (24) and (25) into an output form:

$$
\begin{gathered}
\boldsymbol{M}_{q} \ddot{\boldsymbol{q}}+\boldsymbol{C}_{q} \dot{\boldsymbol{q}}-\boldsymbol{G}_{q}+\boldsymbol{M}_{b} \ddot{\boldsymbol{q}}_{m}+\boldsymbol{C}_{b} \dot{\boldsymbol{q}}_{m}=\boldsymbol{J}^{T} \boldsymbol{f}_{a}=A \boldsymbol{J}^{T} \boldsymbol{p}_{L} \\
\dot{\boldsymbol{q}}=\boldsymbol{H} \dot{\boldsymbol{q}}_{b}+\boldsymbol{T} \dot{\boldsymbol{q}}_{s}
\end{gathered}
$$

where $\boldsymbol{q}$ was the position and posture of the upper platform relative to the inertial system. Since only qualitative analysis on the model was performed, the specific expressions of parameters $M_{q}, C_{q}, G_{q}, M_{b}, C_{b}, H$ and $\boldsymbol{T}$ of the above equations were not given here. The system described above was a strongly coupled nonlinear system. In order to qualitatively analyze the system, the influence of gravity was ignored and analysis at the zero position was carried out. Equations (22), (23), (26) and (27) were combined to obtain the open-loop frequency characteristic of the control system as

$$
\frac{\boldsymbol{q}}{\boldsymbol{x}_{v}}=\frac{\left(\boldsymbol{J}_{l m}^{T}\left(\boldsymbol{M}_{b} s^{2}+\boldsymbol{C}_{b} s\right)+\left(\boldsymbol{M} s^{2}+\boldsymbol{C} s+\boldsymbol{K}\right)\right) K_{q} A}{\boldsymbol{N}(s)}
$$

where $s$ was a differential operator, Ns was expressed as:

$$
\begin{aligned}
\boldsymbol{N}(s)= & \left(\left(C_{r} s+K_{c e}\right)\left(\boldsymbol{M} s^{2}+C s+\boldsymbol{K}\right)+A^{2} s \boldsymbol{J} \boldsymbol{J}_{l m}^{T}\right)\left(\boldsymbol{M}_{q} s^{2}+\boldsymbol{C}_{q} s\right) \\
& +A^{2} s \boldsymbol{J}\left(\boldsymbol{J}_{l m}^{T}\left(\boldsymbol{M}_{b} s^{2}+\boldsymbol{C}_{b} s\right)+\left(\boldsymbol{M}^{2}+\boldsymbol{C} s+\boldsymbol{K}\right)\right)
\end{aligned}
$$

If the Stewart platform was independent of degrees of freedom, that is, if the above matrix was a diagonal matrix, the open-loop frequency characteristic of Equation (28) can be simplified into an integral link, two oscillation links and a differential link. If there were coupling terms between the above matrices, there would be multiple modes for the frequency characteristic.

\subsection{Analysis on Natural Frequency}

From Equation (28), it can be seen that the open-loop frequency characteristic of the system consisted of two oscillation links, a differential link and an integral link. As the dynamic characteristic of the reaction base is quite complex, in our work, the dynamic model of the reaction base is simplified as an uncoupled system, which means $\boldsymbol{K}_{b}$ and $\boldsymbol{C}_{b}$ are both diagonal matrices. The corner frequencies of these links were related to the natural frequency of the base and the hydraulic natural frequency. Therefore, in order to analyze the relationship between the natural frequencies of the two oscillation links, the natural frequency of the power mechanism, and the natural frequency of the base, the effect of 
damping was ignored, and an equivalent model of 12 degrees of freedom was established, as shown in Figure 5.

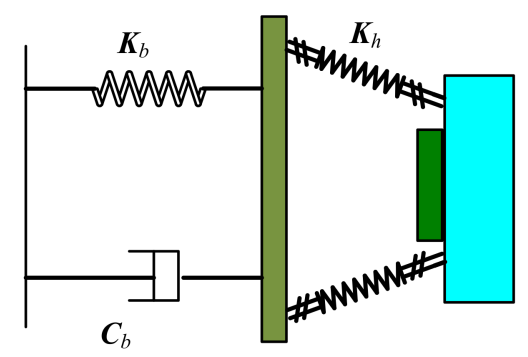

Figure 5. Equivalent model.

In Figure 5, the equivalent spring stiffness of the hydraulic cylinder power mechanism of each leg was:

$$
k_{h i}=4 \frac{\beta_{e} A^{2}}{V_{t}}
$$

where $\beta_{e}$ is bulk modulus of hydraulic oil, and $V_{t}$ is the total chamber volume of hydraulic cylinder.

Then, $\boldsymbol{K}_{h}=\operatorname{diag}\left\{k_{h 1}, k_{h 2}, k_{h 3}, k_{h 4}, k_{h 5}, k_{h 6}\right\}$, and dynamic differential equations of the reaction base and the inertial mass,

$$
\begin{aligned}
& \boldsymbol{M}_{l} \ddot{\boldsymbol{l}}+\boldsymbol{M}_{m} \ddot{\boldsymbol{q}}_{m}=-\boldsymbol{K}_{h} \Delta \boldsymbol{l} \\
& \boldsymbol{M}_{\boldsymbol{q}}+\boldsymbol{K} \boldsymbol{q}_{m}=\boldsymbol{J}_{l m}^{T} \boldsymbol{K}_{h} \Delta \boldsymbol{l}
\end{aligned}
$$

where $\Delta l$ was an array composed of extensions of hydraulic cylinder actuators of respective legs. Equations (29) and (30) were combined to obtain the relationship between the natural frequency of the base, the hydraulic natural frequency, and the natural frequency produced by rigid-flexible coupling, which was expressed by Equation (31).

$$
\left|\left[\begin{array}{cc}
0 & \boldsymbol{K}_{h} \\
-\boldsymbol{J}_{l m}^{T} \boldsymbol{K}_{h} & \boldsymbol{K}
\end{array}\right]-\omega_{n}^{2}\left[\begin{array}{cc}
\boldsymbol{M}_{l} & \boldsymbol{M}_{m} \\
0 & \boldsymbol{M}
\end{array}\right]\right|=0
$$

where $\omega_{n}$ was the natural frequency produced by rigid-flexible coupling. The coupling natural frequency of the open-loop frequency characteristic could be approximately estimated by the above model.

\section{Simulation Research on Influence of Flexible Bases on Frequency Characteristics of Parallel Robot}

Table 1 showed the technical parameters of the parallel robot of the comprehensive test system for the train end relationship. According to the technical parameters, the natural frequencies of the respective degrees of freedom of the parallel robot were $10 \mathrm{~Hz}(\mathrm{Rz}), 17.7$ $\mathrm{Hz}(\mathrm{Ry}), 10.6 \mathrm{~Hz}(\mathrm{Rx}), 9.2 \mathrm{~Hz}(\mathrm{X}), 4.1 \mathrm{~Hz}(\mathrm{Y}), 4.1 \mathrm{~Hz}(\mathrm{Z})$.

When the mass of the back reaction base was $500 \mathrm{~kg}$ and the stiffness variation was set to $2 \times 10^{5} \mathrm{~N} / \mathrm{m}, 2 \times 10^{6} \mathrm{~N} / \mathrm{m}, 2 \mathrm{e} 7 \mathrm{~N} / \mathrm{m}$ and $2 \times 10^{8} \mathrm{~N} / \mathrm{m}$, respectively, the corresponding natural frequency ranges of the base were $3.18,10.06,31.8$ and $100 \mathrm{~Hz}$, respectively. In this paper, only $\mathrm{X}$ and $\mathrm{Y}$ degrees of freedom were used to simulate the frequency characteristics, so as to illustrate the influence of the flexible base on the frequency characteristics of the parallel robot. The results were shown in Figure 6. Simulation results of frequency characteristics along $X$ and $Y$ degrees of freedom with different reaction base stiffnesses were shown in Figure 6. For Figure $6 \mathrm{a}, \mathrm{b}$, the stiffness of the reaction base was set as $2 \times 10^{5} \mathrm{~N} / \mathrm{m}$. For Figure $6 \mathrm{c}, \mathrm{d}$, the stiffness was $2 \times 10^{6} \mathrm{~N} / \mathrm{m}$. For Figure $6 \mathrm{e}, \mathrm{f}$, the stiffness was $2 \times 10^{7} \mathrm{~N} / \mathrm{m}$. For Figure $6 \mathrm{~g}, \mathrm{~h}$, the stiffness was $2 \times 10^{8} \mathrm{~N} / \mathrm{m}$. 
Table 1. Technical parameters of parallel robot.

\begin{tabular}{cc}
\hline Parameters & Value \\
\hline$r_{c}(\mathrm{~mm})$ & 800 \\
$r_{d}(\mathrm{~mm})$ & 1100 \\
$d_{c}(\mathrm{~mm})$ & 200 \\
$d_{d}(\mathrm{~mm})$ & 300 \\
$H s(\mathrm{~mm})$ & 1235.5 \\
$\rho_{p}(\mathrm{~m})$ & $(0 ; 0 ; 0)$ \\
$m_{p}(\mathrm{~kg})$ & 10,000 \\
$I_{p s}(\mathrm{~kg} \mathrm{~m})^{2}$ & $\operatorname{diag}(1908,867,2708)$ \\
$C_{t c}\left(\mathrm{~m}^{3} / \mathrm{s} / \mathrm{Pa}\right)$ & $2 \times 10^{-11}$ \\
$B_{e}(\mathrm{MPa})$ & 690 \\
$Q_{n}(\mathrm{~L} / \mathrm{min})$ & 40 \\
\hline
\end{tabular}

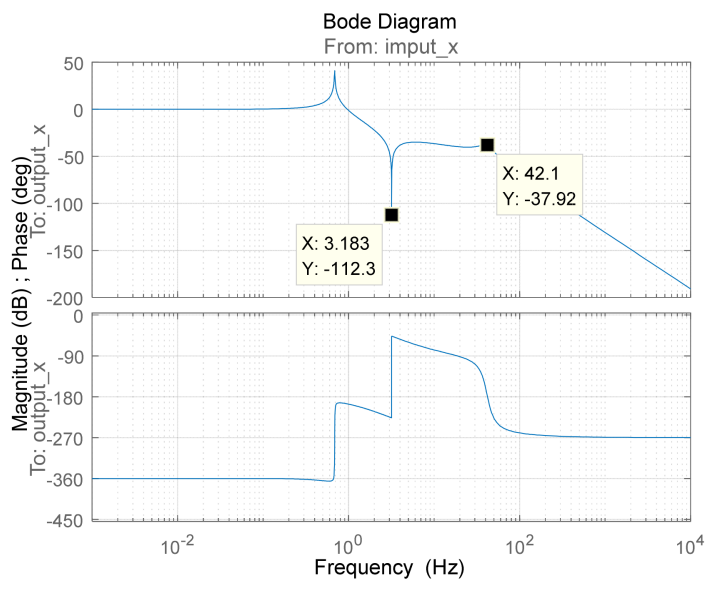

(a) X direction: $K_{b}=2 \times 10^{5} \mathrm{~N} / \mathrm{m}$

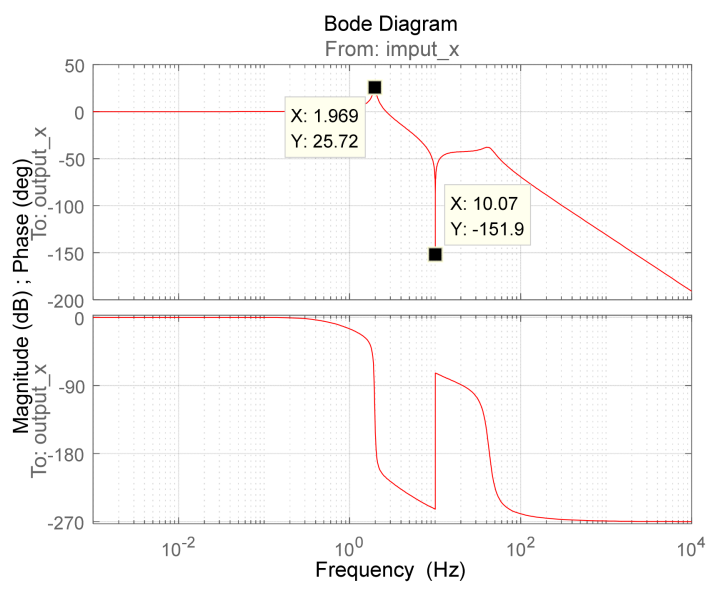

(c) X direction: $K_{b}=2 \times 10^{6} \mathrm{~N} / \mathrm{m}$

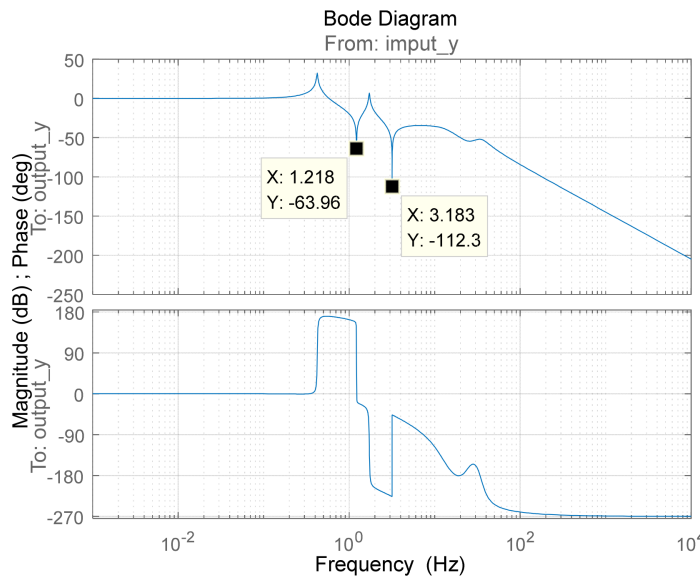

(b) Y direction: $K_{b}=2 \times 10^{5} \mathrm{~N} / \mathrm{m}$

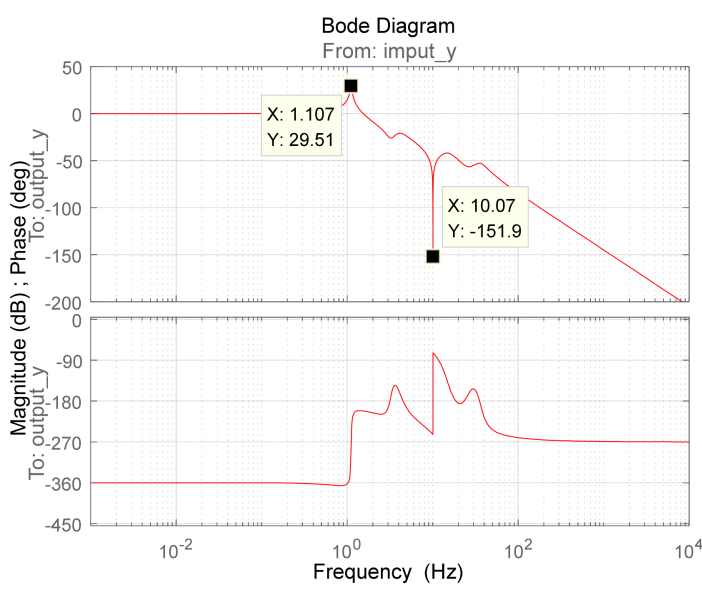

(d) Y direction: $K_{b}=2 \times 10^{6} \mathrm{~N} / \mathrm{m}$

Figure 6. Cont. 


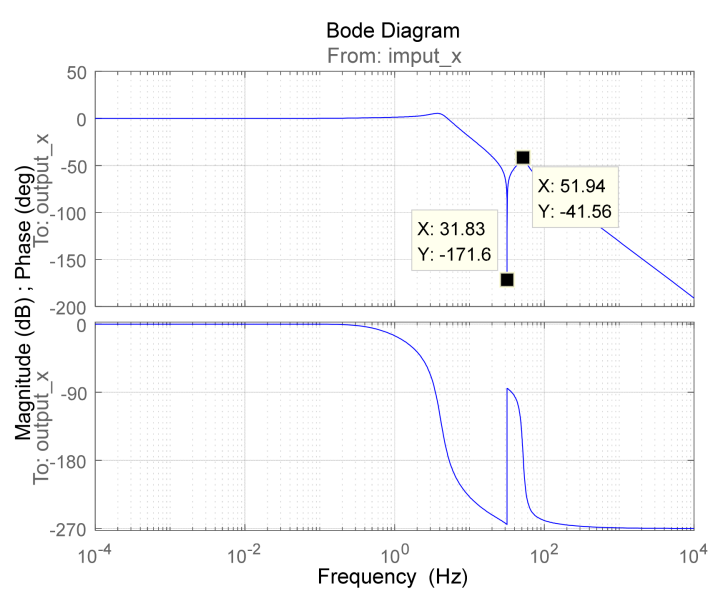

(e) X direction: $K_{b}=2 \times 10^{7} \mathrm{~N} / \mathrm{m}$

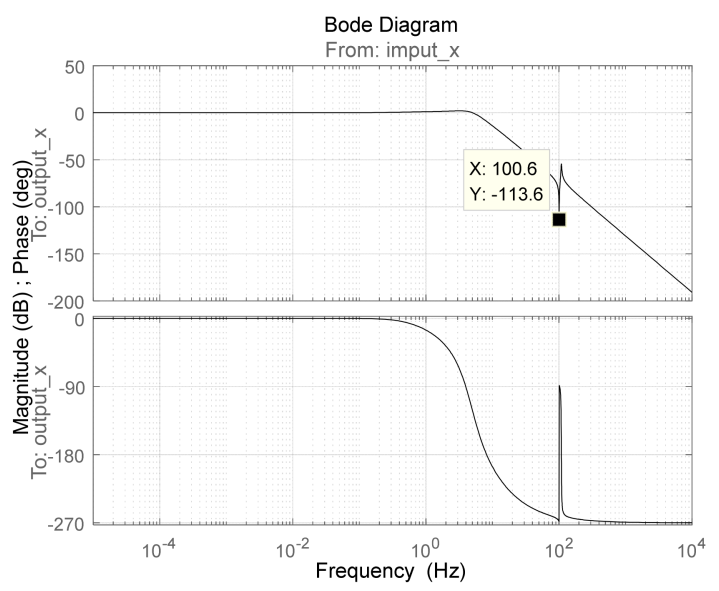

(g) X direction: $K_{b}=2 \times 10^{8} \mathrm{~N} / \mathrm{m}$

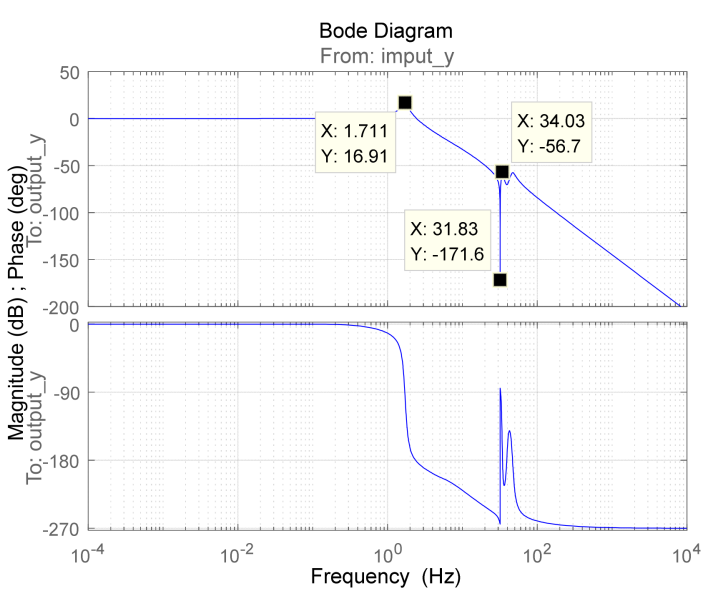

(f) Y direction: $K_{b}=2 \times 10^{7} \mathrm{~N} / \mathrm{m}$

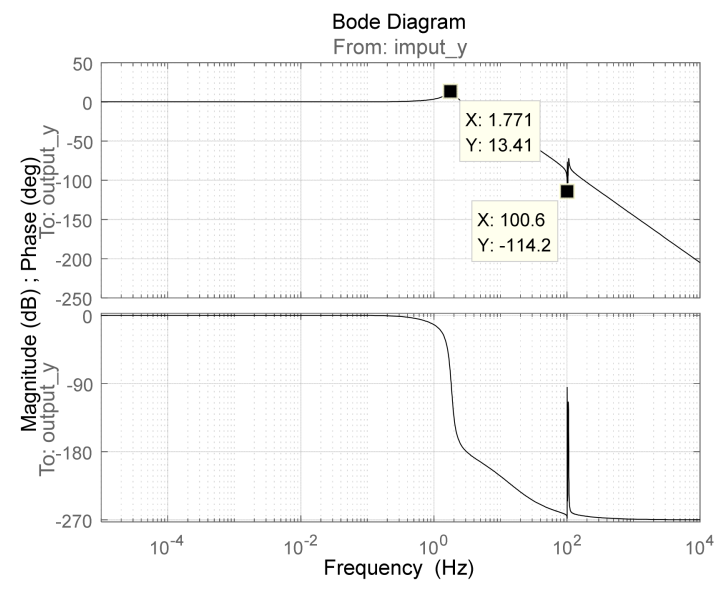

(h) Y direction: $K_{b}=2 \times 10^{8} \mathrm{~N} / \mathrm{m}$

Figure 6. Effect of flexible base on frequency characteristics of control system.

It can be seen from Equation (28) that there was a strong coupling characteristic between the flexible base and the hydraulic system of the parallel robot, resulting in multiple resonance peaks and anti-resonance peaks in the frequency response characteristics of the $X$ and $Y$ degrees of freedom in Figure 6. A similar coupling effect also exists at other degrees of freedom. Moreover, due to the relatively low damping of the flexible base, the amplitude attenuation at the anti-resonance peak frequency point was obvious. If the frequency corresponding to the anti-resonance peak was within the test frequency range, it would seriously affect the loading accuracy of the parallel robot on the train end relationship test-piece. A system with an anti-resonance peak is still able to reproduce the reference signal with satisfactory accuracy, if the actuating force of the parallel robot is large enough. However, based on linear vibration theory, the reaction base in our system would vibrate severely. For the valve-controller electro-hydraulic servo system, there are two ways to improve the actuating force of the system; the first is by increasing the effective area of the hydraulic actuator, and the second is by increasing the pressure of the oil source. The two methods both increase the energy consumption of the system [22].

From Figure $6 \mathrm{a}-\mathrm{h}$, some applicable rules can be found. As the natural frequency of the base increased (the stiffness of the base increased), the frequencies of resonance peaks and anti-resonance peaks, caused by the flexibility of the base, gradually increased, and the frequency characteristics of the test system were gradually improved, i.e., the influence of the flexible base on the performance of the control system was reduced. It can be seen from the curves of (e), (f), (g) and (h) of Figure 6 that, when the natural frequency of the base exceeded five times that of the hydraulic system, the influence of the flexibility of the base within the test bandwidth range on the performance of the control system can be ignored. 
According to our analysis, the first-order natural frequency of the mechanical components of the parallel robot should be at least five times the hydraulic natural frequency. When it exceeds five times, the parallel robot can be regarded as a rigid system, and the performance of the system can be guaranteed through a reasonable controller design. When it is not more than five times, the parallel robot should be regarded as a flexible system. More complicated control algorithms should be adopted to ensure the performance and stability of the system.

\section{Experiment Verifications}

To verify the effectiveness of our analysis, we conducted experiments using a test system for the train end relationship, as shown in Figure 1. The detailed technical parameters are shown in Table 1. The pressure of the oil source is $21 \mathrm{MPa}$. The servo-controller is managed on an industrial personal computer running a hard real-time operating system, and the sample time of the controller is set as $1 \mathrm{~ms}$. A PI controller as shown in Figure 7 is adopted. For a Cartesian desired trajectory $\boldsymbol{q}_{d}$, length of each actuator $\boldsymbol{l}_{d}$ is calculated with Equation (4), and then the PI controller adjusts the drive command depending on $\boldsymbol{l}_{d}$ and the actual length $l$ of each actuator. Detailed design method and stability analysis of the controller can be found in our previous work [23-25]. Parameters of the controller were well tuned, with a trial-and-error method based on the response of the parallel robot in the time domain before experiments.

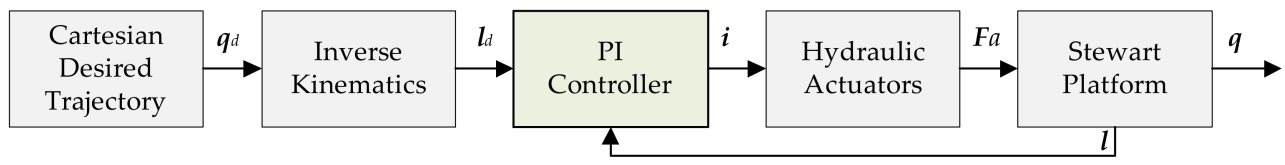

Figure 7. Control block diagram for Stewart platform.

An experiment was conducted of the sinusoidal motion along the $X$ and $Y$ direction, respectively. The experiment result along the $X$ direction is shown in Figure 8, and the result along the $\mathrm{Y}$ direction is shown in Figure 9.

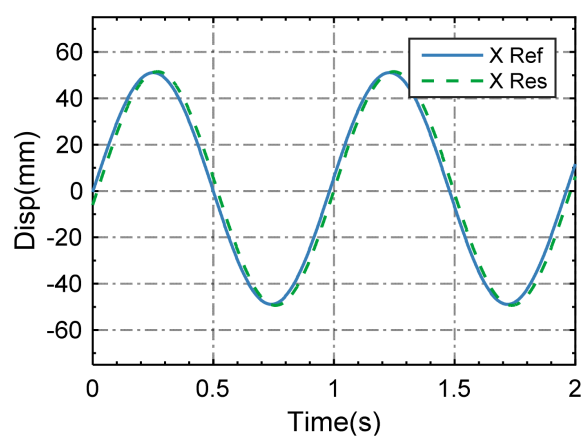

(a) X direction: $1 \mathrm{~Hz} 50 \mathrm{~mm}$

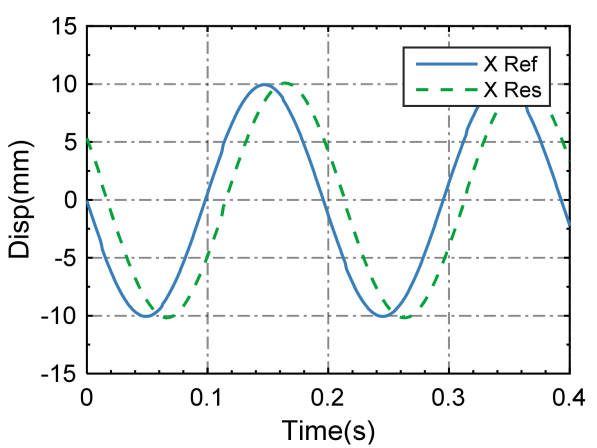

(c) X direction: $5 \mathrm{~Hz} 10 \mathrm{~mm}$

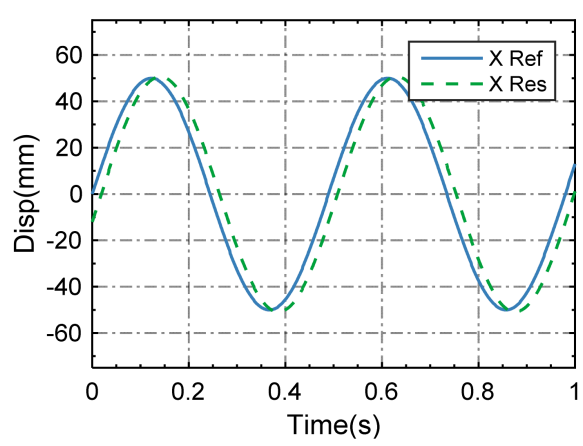

(b) X direction: $2 \mathrm{~Hz} 50 \mathrm{~mm}$

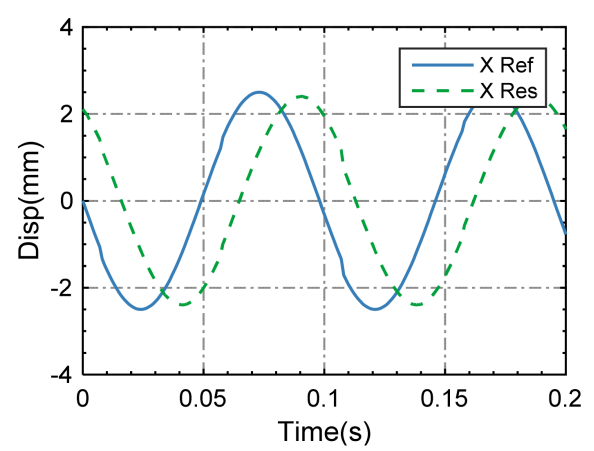

(d) $\mathrm{X}$ direction: $10 \mathrm{~Hz} 2.5 \mathrm{~mm}$

Figure 8. Experiment Result of Sinusoidal along X Direction. 


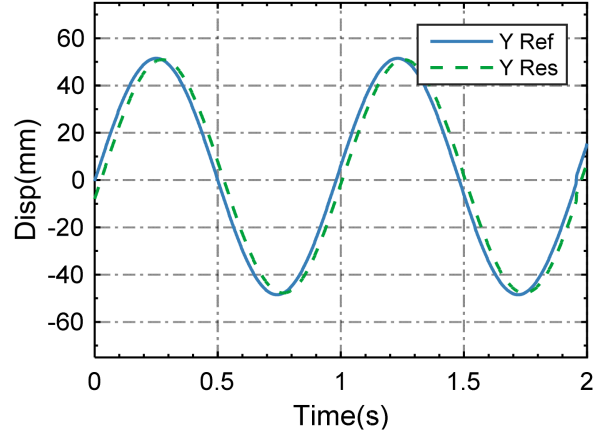

(a) Y direction: $1 \mathrm{~Hz} 50 \mathrm{~mm}$

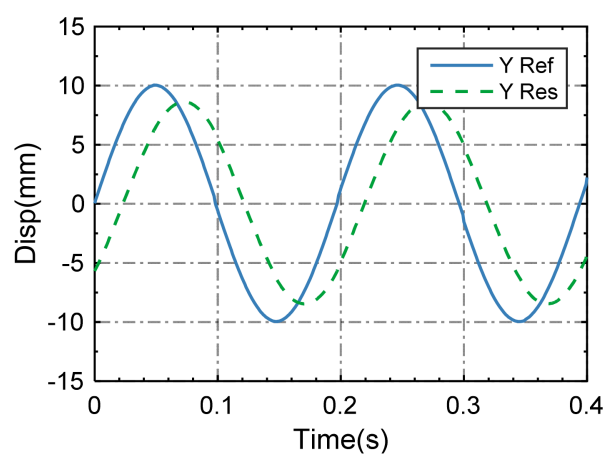

(c) Y direction: $5 \mathrm{~Hz} 10 \mathrm{~mm}$

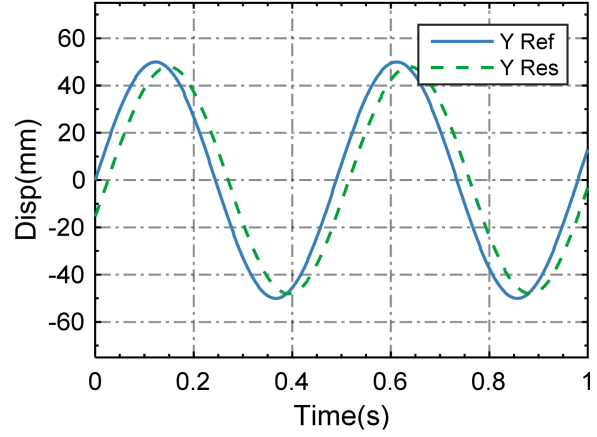

(b) Y direction: $2 \mathrm{~Hz} 50 \mathrm{~mm}$

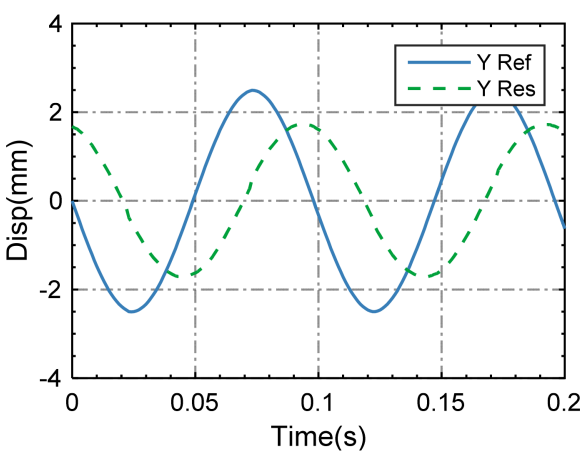

(d) Y direction: $10 \mathrm{~Hz} 2.5 \mathrm{~mm}$

Figure 9. Experiment Result of Sinusoidal along Y Direction.

As shown in Figures 8 and 9, the parallel robot can track the sinusoidal trajectory well with frequency of $1 \mathrm{~Hz}, 2 \mathrm{~Hz}$ and $5 \mathrm{~Hz}$ well (amplitude attenuation better than $-3 \mathrm{~dB}$ and phase delay better than $90^{\circ}$ ). For a trajectory of $10 \mathrm{~Hz}$, the performance of the parallel along the $\mathrm{X}$ direction is better than along the $\mathrm{Y}$ direction.

The experiment's results illustrate that the well-designed Stewart parallel robot with an approximately rigid reaction base can ensure satisfactory performance.

\section{Conclusions}

In this paper, the influence of the flexibility of the base on the frequency performance of the system was analyzed by establishing a comprehensive test system model for the train end relationship under the coupling of the flexible base. When the natural frequency of the base exceeded five times the lowest natural frequency of the hydraulic system, the influence of the flexibility of the base on the test accuracy can be ignored. Furthermore, an important theoretical basis was provided for the design of the test system.

Author Contributions: Conceptualization, Z.Z. and Z.Y.; software, Z.Z. and D.C.; methodology, Z.Z. and Z.Y.; validation, Z.Z., Y.C. and J.H.; formal analysis, Z.Z., Z.Y. and Y.C.; investigation, Z.Z. and D.C.; resources, J.H.; data curation, Z.Z.; writing-original draft preparation, Z.Z. and Y.C.; writingreview and editing, Z.Y. and D.C.; visualization, Z.Y.; supervision, J.H.; project administration, J.H. All authors have read and agreed to the published version of the manuscript.

Funding: This research received no external funding.

Institutional Review Board Statement: Not applicable.

Informed Consent Statement: Not applicable.

Conflicts of Interest: The authors declare no conflict of interest. 


\section{References}

1. Ding, S.S.; Li, Q.; Tian, A.Q.; Du, J.; Liu, J.L. Aerodynamic design on high-speed trains. Acta Mech. Sin. 2016, 32, 215-232. [CrossRef]

2. Yang, G.; Guo, D.; Yao, S.; Liu, C. Aerodynamic design for China new high-speed trains. Sci. China Technol. Sci. 2012, 55, 1923-1928. [CrossRef]

3. Givoni, M. Development and impact of the modern high-speed train: A review. Transp. Rev. 2006, 26, 593-611. [CrossRef]

4. Zhou, H.; Li, H.; Chen, X.; Zhu, C. Analysis of Coupling Between High-Speed Railway and Common Speed Railway System in Transportation Corridor. In Earth and Environmental Science; IOP Conference Series; IOP Publishing: Bristol, UK, 2017; Volume 61, p. 012113.

5. Zhang, W.; Shen, Z.; Zeng, J. Study on dynamics of coupled systems in high-speed trains. Veh. Syst. Dyn. 2013, 51, 966-1016. [CrossRef]

6. Makino, T.; Kato, T.; Hirakawa, K. Review of the fatigue damage tolerance of high-speed railway axles in Japan. Eng. Fract. Mech. 2011, 78, 810-825. [CrossRef]

7. Guo, F.; Wu, S.C.; Liu, J.X.; Zhang, W.; Qin, Q.B.; Yao, Y. Fatigue life assessment of bogie frames in high-speed railway vehicles considering gear meshing. Int. J. Fatigue 2020, 132, 105353. [CrossRef]

8. Lu, C.; Mo, J.; Sun, R.; Wu, Y.; Fan, Z. Investigation into Multiaxial Character of Thermomechanical Fatigue Damage on High-Speed Railway Brake Disc. Vehicles 2021, 3, 287-299. [CrossRef]

9. Bustos, A.; Rubio, H.; Castejón, C.; García-Prada, J.C. EMD-based methodology for the identification of a high-speed train running in a gear operating state. Sensors 2018, 18, 793. [CrossRef]

10. Liu, S.; Yu, Y.; Zhu, Z.; Su, L.; Liu, Q. Dynamic Modeling and Analysis of 3-RRS Parallel Manipulator with Flexible Links. J. Cent. South Univ. Technol. 2010, 17, 323-331. [CrossRef]

11. Zhang, C.; Jiang, H. Rigid-Flexible Modal Analysis of the Hydraulic 6-DOF Parallel Mechanism. Energies 2021, 14, 1604. [CrossRef]

12. Rezaei, A.; Akbarzadeh, A.; Akbarzadeh-T, M.-R. An Investigation on Stiffness of a 3-PSP Spatial Parallel Mechanism with Flexible Moving Platform Using Invariant Form. Mech. Mach. Theory 2012, 51, 195-216. [CrossRef]

13. Sharifnia, M.; Akbarzadeh, A. Dynamics and Vibration of a 3-P SP Parallel Robot with Flexible Moving Platform. J. Vib. Control 2016, 22, 1095-1116. [CrossRef]

14. Wang, G.; Liu, H. Dynamics Model of 4-SPS/CU Parallel Mechanism with Spherical Clearance Joint and Flexible Moving Platform. J. Tribol. 2018, 140, 021101. [CrossRef]

15. Wei, W. Coupling Characteristics Analysis of Redundant Multi-Axis Shaking Table and Research on Its Control Strategy. Ph.D. Thesis, Harbin Institute of Technology Harbin, Harbin, China, 2015.

16. Sharifnia, M.; Akbarzadeh, A. An Analytical Model for Vibration and Control of a P R-P RP Parallel Robot with Flexible Platform and Prismatic Joint. J. Vib. Control 2016, 22, 632-648. [CrossRef]

17. Wu, J.; Wang, J.; Wang, L.; Li, T.; You, Z. Study on the Stiffness of a 5-DOF Hybrid Machine Tool with Actuation Redundancy. Mech. Mach. Theory 2009, 44, 289-305. [CrossRef]

18. Majou, F.; Gosselin, C.; Wenger, P.; Chablat, D. Parametric Stiffness Analysis of the Orthoglide. Mech. Mach. Theory 2007, 42, 296-311. [CrossRef]

19. Yu, Y.; Hongtao, W.; Zhaoming, Z. Stewart sensor dynamics and natural frequency analysis based on Kane method. J. Dyn. Control 2004, 2, 84-87.

20. De Luca, A.; Di Giovanni, G. Rest-to-Rest Motion of a Two-Link Robot with a Flexible Forearm. In Proceedings of the 2001 IEEE/ASME International Conference on Advanced Intelligent Mechatronics. Proceedings (Cat. No.01TH8556), Como, Italy, 8-12 July 2001.

21. Huang, T.; Zhao, X.; Whitehouse, D.J. Stiffness Estimation of a Tripod-Based Parallel Kinematic Machine. IEEE Trans. Robot. Autom. 2002, 18, 50-58. [CrossRef]

22. Merritt, H.E. Hydraulic Control Systems; John Wiley \& Sons: Hoboken, NJ, USA, 1991; ISBN 978-0-471-59617-2.

23. Cai, Y.; Zheng, S.; Liu, W.; Qu, Z.; Zhu, J.; Han, J. Sliding-mode control of ship-mounted Stewart platforms for wave compensation using velocity feedforward. Ocean. Eng. 2021, 236, 109477. [CrossRef]

24. Cai, Y.; Zheng, S.; Liu, W.; Qu, Z.; Zhu, J.; Han, J. Adaptive robust dual-loop control scheme of ship-mounted Stewart platforms for wave compensation. Mech. Mach. Theory 2021, 164, 104406. [CrossRef]

25. Yang, C.; Huang, Q.; Jiang, H.; Peter, O.O.; Han, J. PD control with gravity compensation for hydraulic 6-DOF parallel manipulator. Mech. Mach. Theory 2010, 45, 666-677. [CrossRef] 